$\underset{\text { clinical }}{\text { nephron }}$

Practice
Nephron 2019;143:24-27

DOI: 10.1159/000494512
Received: June 14, 2018

Accepted after revision: October 14, 2018

Published online: January 11, 2019

\title{
Do Endocannabinoids Regulate Glucose Reabsorption in the Kidney?
}

\author{
Liad Hinden Joseph Tam
}

Obesity and Metabolism Laboratory, The Institute for Drug Research, School of Pharmacy, Faculty of Medicine, The Hebrew University of Jerusalem, Jerusalem, Israel

\section{Keywords}

Renal proximal tubule cells · Cannabinoid-1 receptor .

Glucose transporters 2 . Sodium-dependent glucose

cotransporte 2

\begin{abstract}
Diabetic nephropathy (DN), a distinct manifestation of diabetic kidney disease, affects approximately $30 \%$ of patients with diabetes. While most attention has been focused on glomerular changes related to $\mathrm{DN}$, there is growing evidence that tubulopathy is a key feature in the pathogenesis of this disease. The renal proximal tubule cells (RPTCs) are particularly sensitive to the deleterious effect of chronic hyperglycemia. However, the cellular changes that control the dysfunction of the RPTCs are not fully understood. Controlling glucose reabsorption in the proximal tubules via inhibition of glucose transporters (GLUT) has emerged as a promising therapeutic in ameliorating DN. Overactivation of the renal endocannabinoid (eCB) system via the cannabinoid-1 receptor $\left(C_{1} R\right)$ contributes to the development of $D N$, and its blockade by globally acting or peripherally restricted $\mathrm{CB}_{1} \mathrm{R}$ antagonists has been shown to ameliorate renal dysfunction in different murine models for diabetes. Recently, we have utilized various pharmacological and genetic tools to show that the eCB/CB${ }_{1} R$ system contributes to the development of DN via regulating the expression, translocation, and activity of the facilitative GLUT2 located in the RPTCs.
\end{abstract}

These findings have the potential to be translated into therapy, and support the rationale for the preclinical development of novel renal-specific $\mathrm{CB}_{1} \mathrm{R}$ and/or GLUT2 inhibitors for the treatment of DN.

(c) 2019 S. Karger AG, Basel

Glucose reabsorption by renal proximal tubule cells (RPTCs) is usually mediated by 2 central glucose transporters (GLUT): under normoglycemic conditions, the low-affinity high-capacity sodium-dependent glucose cotransporter 2 (SGLT2) is responsible for reabsorbing up to $90 \%$ of filtered glucose across the apical/brush border membrane (BBM) of the RPTCs, and the facilitative GLUT2 is responsible for diffusing the reabsorbed or newly synthesized glucose from the tubular cell back to the bloodstream across the basolateral membrane [1]. While the protein expression levels of SGLT2 in the RPTCs are reported to be elevated in patients with type- 2 diabetes (T2DM) [2,3], others have documented a slight opposite trend in its mRNA expression levels in different sets of patients with T2DM and preserved kidney function $[4,5]$. Reports have been also quite controversial when exploring SGLT2 expression pattern in different

Contribution from the CME Course of the DIABESITY Working Group of the ERA-EDTA, Lisbon, November 24-25, 2017.

\section{KARGER}

(C) 2019 S. Karger AG, Basel

E-Mail karger@karger.com

www.karger.com/nef
Liad Hinden or Joseph Tam

Obesity and Metabolism Laboratory, The Institute for Drug Research

School of Pharmacy, Faculty of Medicine

The Hebrew University of Jerusalem, Jerusalem 9112001 (Israel)

E-Mail liad.hinden@ mail.huji.ac.il or yossit@ekmd.huji.ac.il 
murine models for T1DM and T2DM. For example, SGLT2 has been shown to be upregulated [6, 7], downregulated $[8-10]$, or unchanged $[11,12]$ under different diabetic paradigms. On the other hand, the protein expression of GLUT2 in RPTCs is dramatically increased in diabetic humans [2] as well as in murine models for both diabetes and obesity [12-14]. Additionally, a shift in its localization from the RPTC's basolateral membrane to the BBM, contributing to increased glucose reabsorption during hyperglycemia, was also reported [14-16]. In fact, plasma or luminal glucose concentrations have been shown to regulate GLUT2 expression and/or translocation $[12,17]$. This, in turn, may lead to increased glucose concentration within the proximal tubules, which is suggested to enhance tubular damage.

The recent clinical approval of SGLT2 inhibitors for treating hyperglycemia in diabetic patients, and the ongoing clinical trials to test their efficacy in treating diabetic nephropathy (DN) emphasize the therapeutic potential of inhibiting GLUTs in the kidney. SGLT2 inhibitors block the SGLT2 protein, resulting in glucose excretion and lower blood glucose levels. Although SGLT2 inhibitors were found to be particularly helpful in obese and diabetic patients, a few adverse effects, such as diabetic ketoacidosis [18] as well as genital and urinary tract infection [19] have been reported with the chronic use of SGLT2 inhibitors. In addition, it has been implicated in increasing the risk for acute kidney injury (AKI) owing to the high, unreabsorbed sodium and glucose levels [20], and decreased estimated glomerular filtration rate [21]. Although the EMPA-REG and CANVAS trials did not report an increase in AKI $[22,23]$ in T2DM patients, volume depletion was more common with canagliflozin versus placebo [23]. In fact, post-marketing reports of AKI with SGLT2 inhibitors urged the FDA to revise the labels of the SGLT2 inhibitors in order to minimize the risk of AKI $[21,24]$. Careful consideration should also be noted when prescribing SGLT2 inhibitors for patients with low blood pressure or for individuals with reduced kidney function, since they may acutely reduce their glomerular hyperfiltration [25], and lead to hyperosmolarity and dehydration owing to their diuretic properties [26]. Therefore, renal GLUT2 blockade may be considered a promising strategy for protecting the kidney from the development of DN in these patients, and as a complementary treatment to SGLT2 inhibitors.

The endocannabinoid system, composed of lipidbased endogenous ligands (anandamide and 2-arachidonoylglycerol) that bind to $2 \mathrm{G}$-protein-coupled receptors (GPCRs; known as cannabinoid-1 receptor $\left[\mathrm{CB}_{1} \mathrm{R}\right]$

Do Endocannabinoids Regulate Glucose Reabsorption in the Kidney? and $\mathrm{CB}_{2} \mathrm{R}$ ), is an important biological system that has been implicated in various physiological and pathological processes both in the central nervous system and periphery. $\mathrm{CB}_{1} \mathrm{R}$ is the most abundant GPCR in the mammalian brain; however, it is also present in multiple peripheral tissues at much lower, but functionally relevant densities, such as the kidney (reviewed in [27]). Using murine models for both T1DM and T2DM, several groups have tremendously contributed to our understanding of the role of the endocannabinoid $/ \mathrm{CB}_{1} \mathrm{R}$ system in the development of DN. Under both conditions, the protein and mRNA expression levels of $\mathrm{CB}_{1} \mathrm{R}$ were found to be upregulated in podocytes, mesangial cells, and RPTCs, and its pharmacological inhibition by globally acting or peripherally restricted antagonists ameliorates diabetes-induced renal dysfunction, inflammation, and fibrosis [28-35].

While SGLT2 inhibitors are still under clinical evaluation for the treatment of DN, the current and most effective therapeutic interventions for diabetic kidney disease are blockers of the renin-angiotensin system (RAS) [36]. Interestingly, it was suggested that $\mathrm{CB}_{1} \mathrm{R}$ has the ability to form a heterodimer with type 1 angiotensin II receptor (AT1R) and amplify its activity [37]. Moreover, administering Losartan, an AT1R antagonist, was found to attenuate $\mathrm{DN}$ by downregulating the expression of $\mathrm{CB}_{1} \mathrm{R}$ in podocytes [31]. In addition, $\mathrm{CB}_{1} \mathrm{R}$ blockade inhibits the effect of angiotensin II in cultured human podocytes similarly to losartan, emphasizing the obligatory role of $\mathrm{CB}_{1} \mathrm{R}$ on AT1R signaling in podocytes [31]; however, the influence of $\mathrm{CB}_{1} \mathrm{R}$ antagonism on RAS-mediated hypertension is yet to be investigated. As for SGLT2, we have recently shown that either peripheral blockade or genetic deletion of $\mathrm{CB}_{1} \mathrm{R}$ specifically in the RPTCs did not affect the downregulated renal expression of SGLT2 in 2 type 1 diabetic mouse models [10]. On the other hand, we found that $\mathrm{CB}_{1} \mathrm{R}$ activation or blockade modulates the expression and dynamic membrane translocation of GLUT2 in RPTCs [10]. This, in turn, affects the susceptibility of the diabetic mice to develop DN. First, we reconfirmed the observation that GLUT2 expression is upregulated and recruited to the BBM of the RPTCs during hyperglycemia $[14,15]$, and then we defined, for the first time, that $\mathrm{CB}_{1} \mathrm{R}$ is involved in these processes. Next, using a novel mouse strain that lacks $\mathrm{CB}_{1} \mathrm{R}$ from RPTCs [32], we showed that the renal downregulation of GLUT2 in these mice results in preserved renal function (with little or no signs of renal fibrosis or inflammation) during hyperglycemia. Moreover, knocking down GLUT2 from RPTCs led to the cells' reduced ability to reabsorb glucose, and it alleviates the deleterious effects of hyperglycemia on these cells. Lastly, 
Fig. 1. Proposed mechanism for the involvement of $\mathrm{CB}_{1} \mathrm{R}$ in regulating hyperglycemia-induced GLUT2 translocation to the BBM in RPTCs. Left panel: Hyperglycemia induces the activation of $\mathrm{CB}_{1} \mathrm{R}-\mathrm{G}_{\mathrm{q} / 11^{-} \mathrm{cou}-}$ pled protein, which results in the release of intracellular stores of calcium from the ER. Elevated calcium levels activate PKC- $\beta 1$, which mediates the apical translocation of GLUT2, and the increased entry of glucose from the tubule lumen into the RPTCs, leading to tubular injury and DN. Right panel: Pharmacological blockade or genetic deletion of $\mathrm{CB}_{1} \mathrm{R}$ in the RPTCs results in reduced activation of $\mathrm{G}_{\mathrm{q} / 11}$-coupled protein, and consequently, fewer glucose molecules enter the RPTCs. This, in turn, protects the cells from the deleterious effects of hyperglycemia. The image is adopted from [10]. GLUT2, glucose transporter 2; $\mathrm{CB}_{1} \mathrm{R}$, cannabinoid-1 receptor; ER, endoplasmic reticulum; PKC- $\beta 1$, protein kinase $C$ beta1; GLUT2, glucose transporters 2.

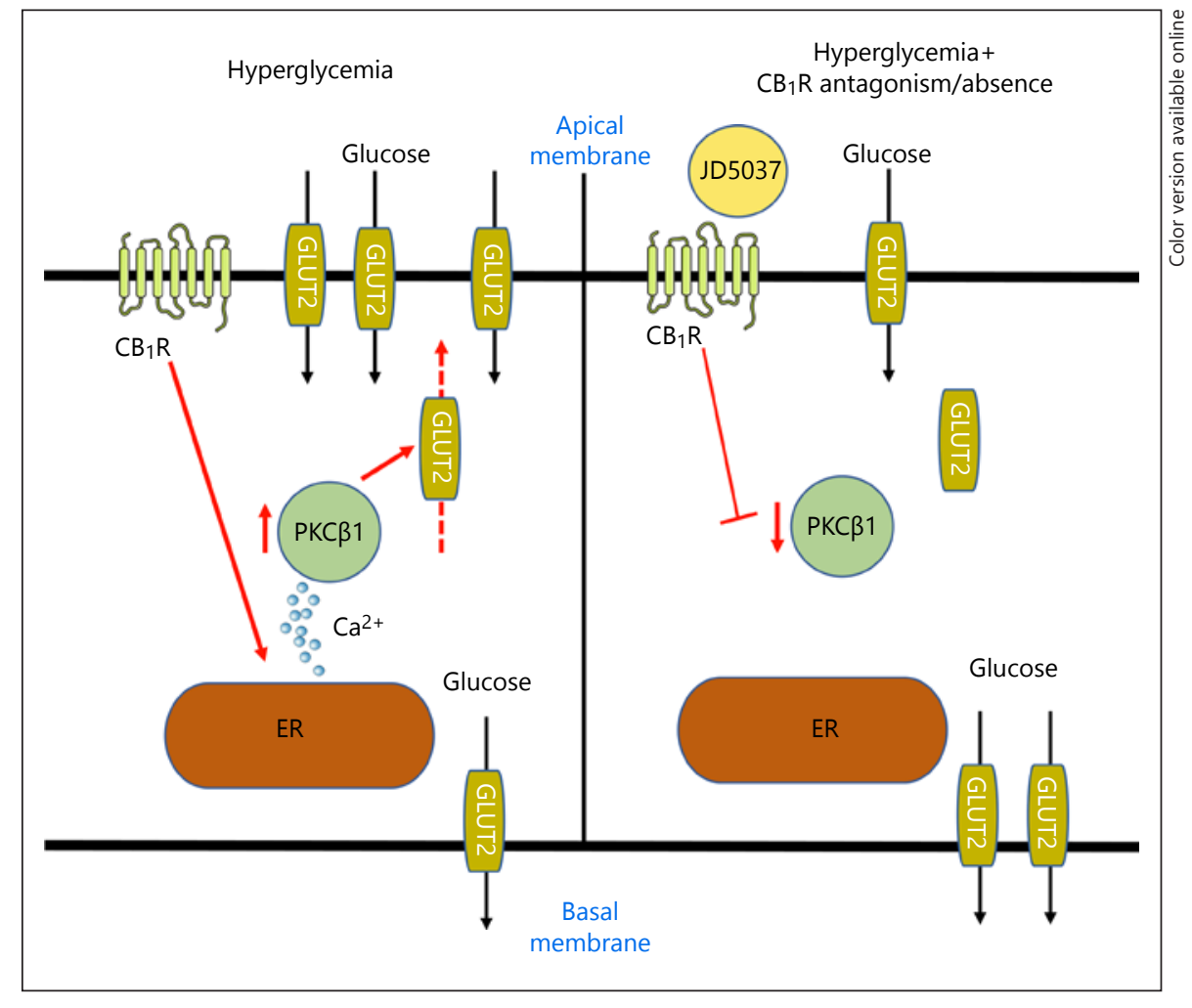

we found that $\mathrm{CB}_{1} \mathrm{R}$ regulates GLUT2 expression, membrane translocation, and activity by a signaling mechanism that involves elevating cytosolic $\mathrm{Ca}^{2+}$ levels and activating the upstream modulator of GLUT2, protein kinase C beta-1 [10] (Fig. 1). The renal protective effect of tubular GLUT2 downregulation, mediated by $\mathrm{CB}_{1} \mathrm{R}$, does not affect blood glucose levels in these mouse models, and therefore, GLUT2 does not possess the risk for the development of ketoacidosis or osmotic diuresis, which in turn, may lead to AKI, as it has been suggested with the use of SGLT2 inhibitors and discussed above. However, the effect of downregulating GLUT2 in RPTCs in models for T2DM has not yet been tested, and therefore, we cannot postulate what would be the effect under this condition.

In conclusion, $\mathrm{CB}_{1} \mathrm{R}$ seems to play a fundamental role in the development of DN via regulating the RAS system, activated during hypertension, and by modulating glucose reabsorption during hyperglycemia. Thus, its inhibition in the kidney, particularly in podocytes and/or RPTCs, has a great potential in treating DN. We also suggest that based on our recent findings, modulating/blocking GLUT2 in the apical membrane of the RPTCs should be further tested preclinically for ameliorating the deleterious effects of hyperglycemia on the kidney.

\section{Acknowledgment}

This work was supported by an ERC-2015-StG grant (\#676841) as well as by the Israel Science Foundation (ISF) grant (\#158/18) to Joseph Tam.

\section{Disclosure Statement}

The authors declare that they have no conflicts of interest to disclose.

References kidney. Kidney Int Suppl 2011;120:S1-S6.

2 Rahmoune H, Thompson PW, Ward JM, Smith CD, Hong G, Brown J: Glucose transporters in human renal proximal tubular cells isolated from the urine of patients with noninsulin-dependent diabetes. Diabetes 2005; 54:3427-3434.

3 Wang XX, Levi J, Luo Y, Myakala K, HermanEdelstein M, Qiu L, Wang D, Peng Y, Grenz A, Lucia S, Dobrinskikh E, D’Agati VD, Koepsell H, Kopp JB, Rosenberg AZ, Levi M: SGLT2 protein expression is increased in human diabetic nephropathy: SGLT2 protein inhibition decreases renallipidaccumulation, inflammation, and the development of nephropathy in diabetic mice. J Biol Chem 2017;292:5335-5348. 
4 Solini A, Rossi C, Mazzanti CM, Proietti A, Koepsell H, Ferrannini E: Sodium-glucose cotransporter (SGLT)2 and SGLT1 renal expression in patients with type 2 diabetes. Diabetes Obes Metab 2017;19:1289-1294.

5 Norton L, Shannon CE, Fourcaudot M, Hu C, Wang N, Ren W, Song J, Abdul-Ghani M, DeFronzo RA, Ren J, Jia W: Sodium-glucose cotransporter (SGLT) and glucose transporter (GLUT) expression in the kidney of type 2 diabetic subjects. Diabetes Obes Metab 2017; 19:1322-1326.

6 Osorio H, Coronel I, Arellano A, Franco M, Escalante B, Bautista R: Ursodeoxycholic acid decreases sodium-glucose cotransporter (SGLT2) expression and oxidative stress in the kidney of diabetic rats. Diabetes Res Clin Pract 2012;97:276-282.

7 Vallon V, Gerasimova M, Rose MA, Masuda T, Satriano J, Mayoux E, Koepsell H, Thomson SC, Rieg T: SGLT2 inhibitor empagliflozin reduces renal growth and albuminuria in proportion to hyperglycemia and prevents glomerular hyperfiltration in diabetic Akita mice. Am J Physiol Renal Physiol 2014; 306:F194-F204.

8 Albertoni Borghese MF, Majowicz MP, Ortiz MC, Passalacqua Mdel R, Sterin Speziale NB, Vidal NA: Expression and activity of SGLT2 in diabetes induced by streptozotocin: relationship with the lipid environment. Nephron Physiol 2009;112:p45-p52.

9 Vallon V, Rose M, Gerasimova M, Satriano J, Platt KA, Koepsell H, Cunard R, Sharma K, Thomson SC, Rieg T: Knockout of Na-glucose transporter SGLT2 attenuates hyperglycemia and glomerular hyperfiltration but not kidney growth or injury in diabetes mellitus. Am J Physiol Renal Physiol 2013;304:F156F167.

10 Hinden L, Udi S, Drori A, Gammal A, Nemirovski A, Hadar R, Baraghithy S, Permyakova A, Geron M, Cohen M, TsytkinKirschenzweig S, Riahi Y, Leibowitz G, Nahmias Y, Priel A, Tam J: Modulation of renal GLUT2 by the cannabinoid-1 receptor: implications for the treatment of diabetic nephropathy. J Am Soc Nephrol 2018;29:434448.

11 Gangadharan Komala M, Gross S, Mudaliar H, Huang C, Pegg K, Mather A, Shen S, Pollock CA, Panchapakesan U: Inhibition of kidney proximal tubular glucose reabsorption does not prevent against diabetic nephropathy in type 1 diabetic eNOS knockout mice. PLoS One 2014;9:e108994.

12 Chichger H, Cleasby ME, Srai SK, Unwin RJ, Debnam ES, Marks J: Experimental type II diabetes and related models of impaired glucose metabolism differentially regulate glucose transporters at the proximal tubule brush border membrane. Exp Physiol 2016; 101:731-742.
13 Chin E, Zamah AM, Landau D, Gronbcek H, Flyvbjerg A, LeRoith D, Bondy CA: Changes in facilitative glucose transporter messenger ribonucleic acid levels in the diabetic rat kidney. Endocrinology 1997;138:1267-1275.

14 Marks J, Carvou NJ, Debnam ES, Srai SK, Unwin RJ: Diabetes increases facilitative glucose uptake and GLUT2 expression at the rat proximal tubule brush border membrane. J Physiol 2003;553:137-145.

15 Cohen M, Kitsberg D, Tsytkin S, Shulman M, Aroeti B, Nahmias Y: Live imaging of GLUT2 glucose-dependent trafficking and its inhibition in polarized epithelial cysts. Open Biol 2014;4:pii:140091.

16 Dominguez JH, Camp K, Maianu L, Feister H, Garvey WT: Molecular adaptations of GLUT1 and GLUT2 in renal proximal tubules of diabetic rats. Am J Physiol 1994;266:F283-F290.

17 Thorens B: Glucose transporters in the regulation of intestinal, renal, and liver glucose fluxes. Am J Physiol 1996;270:G541-G553.

18 Taylor SI, Blau JE, Rother KI: SGLT2 Inhibitors may predispose to ketoacidosis. J Clin Endocrinol Metab 2015;100:2849-2852.

19 Geerlings S, Fonseca V, Castro-Diaz D, List J, Parikh S: Genital and urinary tract infections in diabetes: impact of pharmacologically-induced glucosuria. Diabetes Res Clin Pract 2014;103:373-381.

20 Hahn K, Ejaz AA, Kanbay M, Lanaspa MA, Johnson RJ: Acute kidney injury from SGLT2 inhibitors: potential mechanisms. Nat Rev Nephrol 2016;12:711-712.

21 Desai M, Yavin Y, Balis D, Sun D, Xie J, Canovatchel W, Rosenthal N: Renal safety of canagliflozin, a sodium glucose co-transporter 2 inhibitor, in patients with type 2 diabetes mellitus. Diabetes Obes Metab 2017;19:897-900.

22 Parving $\mathrm{H}-\mathrm{H}$, Lambers-Heerspink $\mathrm{H}$, de Zeeuw D: Empagliflozin and progression of kidney disease in type 2 diabetes. $\mathrm{N}$ Engl J Med 2016;375:1800-1801.

23 Neal B, Perkovic V, Mahaffey KW, de Zeeuw D, Fulcher G, Erondu N, Shaw W, Law G, Desai M, Matthews DR; CANVAS Program Collaborative Group: Canagliflozin and cardiovascular and renal events in type 2 diabetes. $\mathrm{N}$ Engl J Med 2017;377:644-657.

24 FDA Drug Safety Communication: FDA Strengthens Kidney Warnings for Diabetes Medicines Canagliflozin (Invokana, Invokamet) and Dapagliflozin (Farxiga, Xigduo XR), 2016.

25 Fioretto P, Zambon A, Rossato M, Busetto L, Vettor R: SGLT2 inhibitors and the diabetic kidney. Diabetes Care 2016;39(suppl 2):S165S171.

26 Johnsson K, Johnsson E, Mansfield TA, Yavin Y, Ptaszynska A, Parikh SJ: Osmotic diuresis with SGLT2 inhibition: analysis of events related to volume reduction in dapagliflozin clinical trials. Postgrad Med 2016;128:346-355.
27 Pacher P, Kunos G: Modulating the endocannabinoid system in human health and disease - successes and failures. FEBS J 2013;280: 1918-1943.

28 Barutta F, Corbelli A, Mastrocola R, Gambino R, Di Marzo V, Pinach S, Rastaldi MP, Perin PC, Gruden G: Cannabinoid receptor 1 blockade ameliorates albuminuria in experimental diabetic nephropathy. Diabetes 2010; 59:1046-1054.

29 Jenkin KA, McAinch AJ, Zhang Y, Kelly DJ, Hryciw DH: Elevated cannabinoid receptor 1 and $G$ protein-coupled receptor 55 expression in proximal tubule cells and whole kidney exposed to diabetic conditions. Clin Exp Pharmacol Physiol 2015;42:256-262.

30 Nam DH, Lee MH, Kim JE, Song HK, Kang YS, Lee JE, Kim HW, Cha JJ, Hyun YY, Kim SH, Han SY, Han KH, Han JY, Cha DR: Blockade of cannabinoid receptor 1 improves insulin resistance, lipid metabolism, and diabetic nephropathy in $\mathrm{db} / \mathrm{db}$ mice. Endocrinology 2012;153:1387-1396.

31 Jourdan T, Szanda G, Rosenberg AZ, Tam J, Earley BJ, Godlewski G, Cinar R, Liu Z, Liu J, Ju C, Pacher P, Kunos G: Overactive cannabinoid 1 receptor in podocytes drives type 2 diabetic nephropathy. Proc Natl Acad Sci U S A 2014;111:E5420-E5428.

32 Udi S, Hinden L, Earley B, Drori A, Reuveni N, Hadar R, Cinar R, Nemirovski A, Tam J: Proximal tubular cannabinoid-1 receptor regulates obesity-induced CKD. J Am Soc Nephrol 2017;28:3518-3532.

33 Lim JC, Lim SK, Park MJ, Kim GY, Han HJ, Park SH: Cannabinoid receptor 1 mediates high glucose-induced apoptosis via endoplasmic reticulum stress in primary cultured rat mesangial cells. Am J Physiol Renal Physiol 2011;301:F179-F188.

34 Lin CL, Hsu YC, Lee PH, Lei CC, Wang JY, Huang YT, Wang SY, Wang FS: Cannabinoid receptor 1 disturbance of PPARgamma2 augments hyperglycemia induction of mesangial inflammation and fibrosis in renal glomeruli. J Mol Med (Berl) 2014;92:779-792.

35 Jourdan T, Park JK, Varga ZV, Paloczi J, Coffey NJ, Rosenberg AZ, Godlewski G, Cinar R, Mackie K, Pacher P, Kunos G: Cannabinoid-1 receptor deletion in podocytes mitigates both glomerular and tubular dysfunction in a mouse model of diabetic nephropathy. Diabetes Obes Metab 2018;20:698-708.

36 Romagnani P, Remuzzi G, Glassock R, Levin A, Jager KJ, Tonelli M, Massy Z, Wanner C, Anders HJ: Chronic kidney disease. Nat Rev Dis Primers 2017;3:17088.

37 Rozenfeld R, Gupta A, Gagnidze K, Lim MP, Gomes I, Lee-Ramos D, Nieto N, Devi LA: AT1R-CB(1)R heteromerization reveals a new mechanism for the pathogenic properties of angiotensin II. EMBO J 2011;30:23502363.
Do Endocannabinoids Regulate Glucose Reabsorption in the Kidney?
Nephron 2019;143:24-27 DOI: $10.1159 / 000494512$ 